\title{
Crystal and Molecular Structure of 4,6-Bis(nitroimino)-1,3,5-triazinan-2-one: Theoretical and X-ray Studies
}

\author{
P. N. Simões,,$^{* \dagger}$ L. M. Pedroso,${ }^{\dagger}$ A. M. Matos Beja, ${ }^{\ddagger}$ M. Ramos Silva, Elizabeth MacLean,, and \\ A. A. Portugal ${ }^{\dagger}$ \\ Departamento de Engenharia Química, Universidade de Coimbra 3030-290 Coimbra, Portugal, Departamento \\ de Física, Universidade de Coimbra 3004-516 Coimbra, Portugal, and CCLRC Daresbury Laboratory, \\ Daresbury, Warrington, Cheshire, WA44AD, U.K.
}

Received: July 14, 2006; In Final Form: October 27, 2006

\begin{abstract}
This paper provides an overview of recent progress on structural data on the title compound. Theoretical work based on quantum mechanical calculations was performed to gain some understanding on the heterocyclic tautomerism potentially exhibited by the compound. The computational studies encompassed a wide range of tautomers/conformers, allowing the determination of the most probable molecular structure. In the gas phase, the nitroimine tautomers are computed to be substantially more stable than the nitramine tautomers. Among three plausible nitroimine forms, special attention was given to 4,6-bis(nitroimino)-1,3,5-triazinan-2-one, whose crystal structure was unequivocally solved by X-ray diffraction. The crystals are orthorhombic, space group Pnma with $a=6.187(2) \AA, b=13.252(5) \AA, c=8.802(4) \AA$, and $Z=4$. The structure was solved by direct methods and refined to a final $R=0.0326$. The molecule has an approximate mirror plane relating the two symmetry related halves. The nitroimine groups are positioned in a syn-syn conformation. The least-squares (LS) plane of the heterocyclic ring and the nitroimine $\left(=\mathrm{N}-\mathrm{NO}_{2}\right)$ substituent LS plane make an angle of $10.05(11)^{\circ}$. The crystal structure is held together via hydrogen bonds that assemble the molecules in chains running along the $b$-axis. Every $\mathrm{H}$-atom is involved in bifurcated hydrogen bonds.
\end{abstract}

\section{Introduction}

The search for new and improved energetic materials, suitable for use as explosives, propellants, or pyrotechnics, is a recurrent challenge. Being an optimization task, it must obey to a tight tradeoff between performance, safety, and cost. This is accomplished by combining known chemical compounds (formulation) and/or producing new compounds (synthesis). Nitramino-1,3,5-triazines constitute a subclass of nitramines, which are one of the most important category of energetic molecules. ${ }^{1,2}$ Primary nitramines (I), unlike their secondary counterparts (II), are prone to a prototropic (nitro)amine-(nitro)imine tautomerism $^{3}$ (N-nitroimines, also called nitrimines, are compounds having the structure $\mathrm{R}_{2} \mathrm{C}=\mathrm{N}-\mathrm{NO}_{2}$ ), depending on the particular structure of the substituent. Several studies on compounds in which nitroamine-nitroimine tautomerism is virtually possible have been reported. Nitrated derivatives of guanidine ${ }^{4-13}$ and pyridine ${ }^{14-20}$ appear to be more thoroughly studied than others, such as some nitrated heterocycles, ${ }^{21-24}$ as well as phenilnitramines. ${ }^{25}$

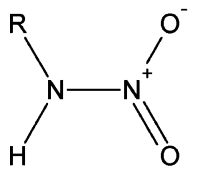

I

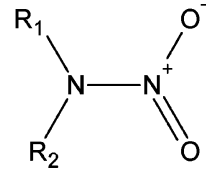

II
* Corresponding author. E-mail: pnsim@eq.uc.pt. Tel.: +351-239798732.

† Departamento de Engenharia Química.

$\doteqdot$ Departamento de Física.

$\S$ CCLRC Daresbury Laboratory.
A nitramine originally named as (di)nitroammeline (hereafter referred as DNAM) had been reported for the first time five decades ago. ${ }^{26}$ While studying the nitration of melamine, Atkinson $^{26}$ proposed no detailed structural formula for the nitrated product, whose characterization also was not fully elucidated at that time. The nitrated product had been reported as having the structure III without any further information on the tautomerism potentially revealed by DNAM.<smiles>[X][N+](=O)Nc1nc(O)nc(N[N+](=O)[O-])n1</smiles>

More recently, we started a study in which DNAM was faced as a potential candidate in the field of energetic materials, namely, in propellant formulations. ${ }^{27-29}$ This study revealed interesting properties of this energetic molecule from two perspectives: the application and the fundamental chemistry of nitramines. With respect to the latter, a fundamental knowledge is to be pursued for a better understanding of the causes that can explain several characteristics whose manifestation has already been identified. Issues such as the prevailing tautomeric forms and correspondent conformers, magnetic properties, acidity, thermal stability, etc., are to be studied in some detail.

Structure III suggests that DNAM can be classified as a primary nitramine. However, as mentioned, some primary nitramines tend to exhibit a nitramine-nitroimine tautomerism. Actually at a glance, structure III indicates that the characteriza- 
TABLE 1: Structures and Atom Numbering of Starting Forms of DNAM for Theoretical Calculations<smiles>CN([O-])c1nc(N(C)O)nc(=O)n1O</smiles><smiles>[2H]N([O-])c1nc(N(C)[N+](=O)[O-])n(N)c(=O)n1</smiles><smiles>CN(C)c1nc(N(C)[N+](=O)[O-])n(C)c(=O)n1</smiles><smiles>CN(c1nc([N+](=O)[O-])nc(=O)n1N)[N+](=O)[O-]</smiles>

NAC4<smiles>CN(c1nc(=O)nc(N(C)[N+](=O)[O-])n1C)[N+](=O)[O-]</smiles>

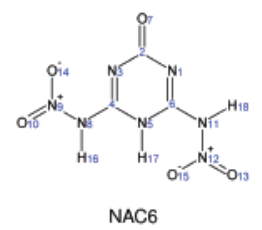<smiles>CN(O)c1nc(=O)nc(N(C)O)n1CO</smiles>

NAC7<smiles>CCCCN([O-])c1nc(O)nc(N([O-])[N+](=O)[O-])n1</smiles><smiles>Cn1c(=O)n(C)c(=N[N+](=O)[O-])n(C)c1=N[N+](=O)[O-]</smiles>

NIC2<smiles></smiles>

NIE2
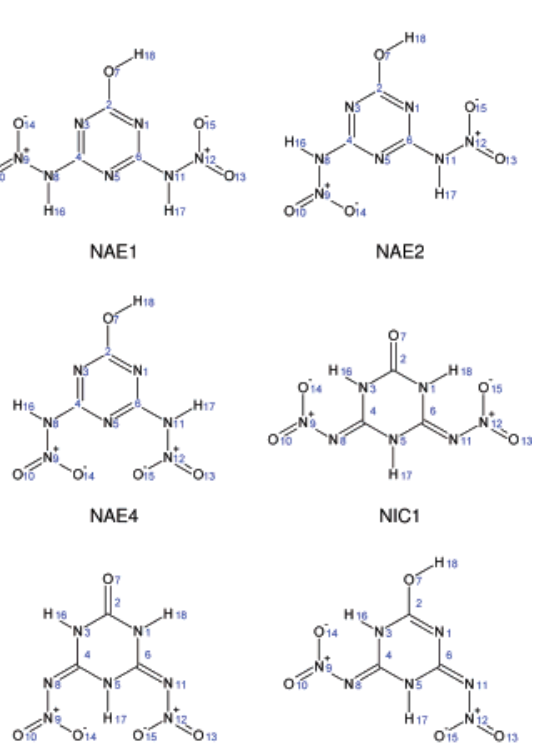

NIC3

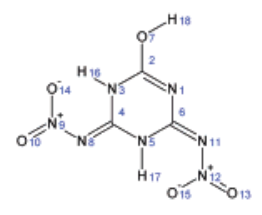

NIE1
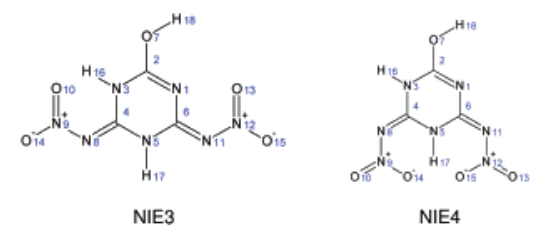

NIE4

tion of the molecular structure is not a straightforward issue in the case of DNAM. A close scrutiny indicates a variety of forms, including a survey of all possible tautomers and conformers (accounting for different rotamers): keto and enolic forms; nitramine and nitroimine forms; aci-nitro forms; and, possibly, structures that combine the mentioned forms.

According to our experience, DNAM reveals some peculiarities that make its theoretical study performed by empirical or semiempirical methods a source of misleading results. More reliable theoretical methods are then necessary to allow a trustworthy screening of structural characteristics of DNAM. This paper reports the results of a systematic theoretical study based on accurate quantum mechanical calculations toward understanding the heterocyclic tautomerism potentially exhibited by the compound. Ab initio and, mainly, density functional theory (DFT) methods with a considerable variety of basis sets were used in the computations. An X-ray crystallographic study was performed to clarify the prevailing tautomeric form in crystalline DNAM and, thus, leading to the respective structural data. In the comparative analysis based on the results from

TABLE 2: Crystal Data and Structure Refinement for 4,6-bis(nitroimino)-1,3,5-triazinan-2-one

\begin{tabular}{ll}
\hline empirical formula & $\mathrm{C}_{3} \mathrm{H}_{3} \mathrm{~N}_{7} \mathrm{O}_{5}$ \\
formula weight & 217.12 \\
temperature $(\mathrm{K})$ & $150(2)$ \\
wavelength $(\AA)$ & 0.6868 \\
crystal system & orthorhombic \\
space group & $P n m a$ \\
$a(\AA)$ & $6.187(2)$ \\
$b(\AA)$ & $13.252(5)$ \\
$c(\AA)$ & $8.802(4)$ \\
volume $\left(\AA^{3}\right)$ & $721.7(5)$ \\
$\mathrm{Z}$ & 4 \\
calculated density $\left(\mathrm{g} / \mathrm{cm}^{3}\right)$ & 1.998 \\
absorption coefficient $\left(\mathrm{mm}^{-1}\right)$ & 0.186 \\
$\mathrm{~F}($ OOO) & 440 \\
crystal size (mm $\left.{ }^{3}\right)$ & $0.02 \times 0.01 \times 0.01$ \\
$\theta$ range for data collection $(\mathrm{deg})$. & $2.68-22.41$ \\
index ranges & $-6<h<5,-14<k<11$, \\
& $-9<l<9$ \\
reflections collected/unique & $2914 / 535[R($ int $)=0.0396]$ \\
completeness to $\theta=22.41$ & $99.3 \%$ \\
refinement method & full-matrix least-squares on $F^{2}$ \\
data/restraints/parameters & $535 / 0 / 80$ \\
goodness-of-fit on $F^{2}$ & 1.041 \\
final R indices $[I>2 \sigma(I)]$ & $R 1=0.0326 w R 2=0.0763$ \\
$\mathrm{R}$ indices $($ all data) & $R 1=0.0472 w R 2=0.0835$ \\
largest diff peak and hole $\left(\mathrm{e} \AA^{-3}\right)$ & 0.202 and -0.264
\end{tabular}

computations and those obtained experimentally, emphasis is put on the geometrical parameters of the molecular system studied.

\section{Methods}

2.1. Computational Details. Theoretical studies on primary nitramines or their nitroimine counterparts are rather lacking. This is particularly true for DNAM and, thus, our attention was focused on a thorough search on this domain. From among a variety of structures that were studied, only those predicted to be the more stable ones will be considered here (nitramine aci forms were discharged after a preliminary study). The starting structures and respective atom numbering used in theoretical calculations are shown in Table 1 . The tautomers/rotamers include the nitramine $\left(-\mathrm{NHNO}_{2}\right)$, keto $(>\mathrm{C}=\mathrm{O})$ and enol $(-\mathrm{OH})$ moieties (NAC and NAE series), as well as the nitroimine $\left(=\mathrm{N}-\mathrm{NO}_{2}\right)$, keto and enol (NAC and NAE series) moieties (NIC and NAE series).

All calculations here reported were performed with the Gaussian98 package. ${ }^{30}$ Despite the good acceptance of quantum chemical methods based on DFT, ${ }^{31,32}$ our wish was to include in our studies traditional ab initio methods as well, such as second-order Møller-Plesset (MP2). ${ }^{33}$ With MP2 being one of the least expensive electron correlation methods, it still needs considerable computational resources, namely, when it is applied to our target molecular system. Because of this limitation, a direct comparison of DFT and ab initio (MP2) methods was made possible only for the basis set 6-31G(d). However, a noticeable piece of work has been carried out within the DFT framework by applying a large range of basis sets. The computations were performed using the Becke-style 3-parameter DFT using the Lee-Yang-Parr correlation functional (B3LYP). ${ }^{34-36}$ A total of 16 Pople kind basis sets ${ }^{37-41}$ from 6-31G(d) to $6-311++\mathrm{G}(3 \mathrm{df}, 3 \mathrm{dp})$ as well as the aug-cc-pVQZ Dunning correlation-consistent basis set ${ }^{42}$ (to mimic the complete basis set limit) were employed to study the molecular form of DNAM known to exist in the crystal.

The tautomers/conformers shown in Table 1 were initially considered with planar symmetry. Molecular geometries were 


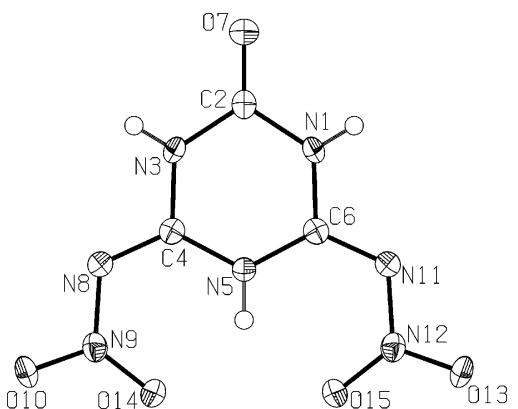

Figure 1. ORTEP diagram of 4,6-bis(nitroimino)-1,3,5-triazinan-2one. The ellipsoids are drawn at the $50 \%$ probability level.

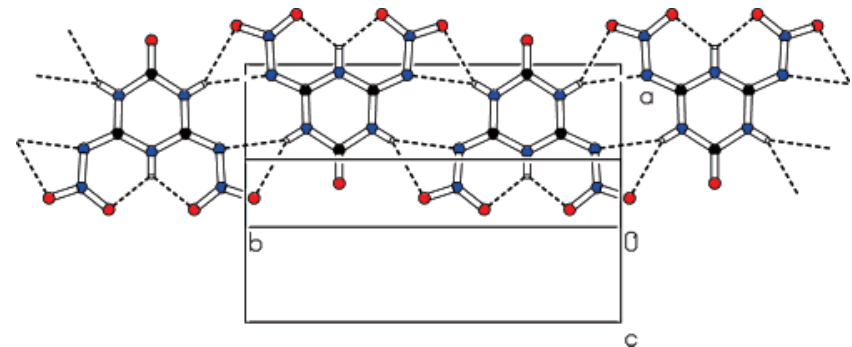

Figure 2. Diagram showing the chain formation via hydrogen bonds $\mathrm{N} 1-\mathrm{H} \cdots \mathrm{O} 13$ : distance donor-H, 0.78(3) $\AA$; distance $\mathrm{H}$-acceptor, 2.37 -

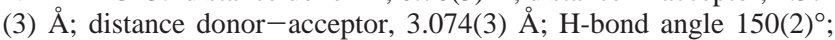
acceptor site symmetry $2-x,-y, 1-z . \mathrm{N} 1-\mathrm{H} \cdot \cdots \mathrm{N} 11$ : distance donorH, 0.78(3) $\AA$; distance H-acceptor, 2.48(3) $\AA$; distance donor-acceptor,

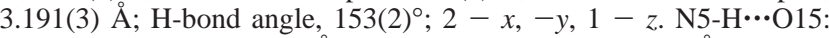
distance donor-H, 0.84(4) $\AA$; distance $\mathrm{H}$-acceptor, 1.94(3) $\AA$; distance donor-acceptor, 2.547(3) $\AA$; H-bond angle, $128.4(11)^{\circ} ; x, 0.5-y, z$.

fully optimized at the levels B3LYP/6-31G(d) and MP2/6-31G(d) by the force gradient method using the Berny algorithm ${ }^{43}$ and applying the tight built in convergence criteria. ${ }^{30}$ In all cases, the nature of the stationary points (minimum) was confirmed by harmonic frequency calculations. The structures found to have imaginary frequencies were reoptimized without any symmetry constraints. A similar procedure was followed when the number of structures was restricted and larger basis sets were used. All calculations were performed in the gas phase.

2.2. Experimental. DNAM was synthesized and purified according to established methods. ${ }^{26}$ The sample was examined and data was collected using the microcrystal diffraction facility on station $9.8^{44,45}$ of the Synchrotron Radiation Source, CCLRC Daresbury Laboratory.

The data was collected on a Bruker Nonius APEX II chargecoupled device (CCD) area-detector diffractometer. ${ }^{46}$ The crystal was mounted on the end of a two-stage glass fiber with perfluoropolyether oil and cooled by a Cryostream nitrogen gas stream. ${ }^{47}$ The wavelength was calibrated by the measurement of the unit cell parameters of a standard crystal of known structure. Data collection nominally covered a hemisphere of reciprocal space by two series of $\omega$-rotation exposure frames with different crystal orientation $\phi$ angles. Reflection intensities were integrated using standard procedures, ${ }^{48}$ allowing for the plane-polarized nature of the primary synchrotron beam. Corrections were applied semiempirically for absorption and incident beam decay. ${ }^{48}$ Unit cell parameters were refined from the observed angles of all strong reflections in the complete data sets.

The structure was solved by direct methods using SHELXS97 program ${ }^{49}$ and refined on $F^{2}$ values by full-matrix least-squares with SHELXL97 program. $^{49}$ The anisotropic displacement parameters for non-hydrogen atoms were refined. Hydrogen atoms were located in a Fourier difference map and refined with

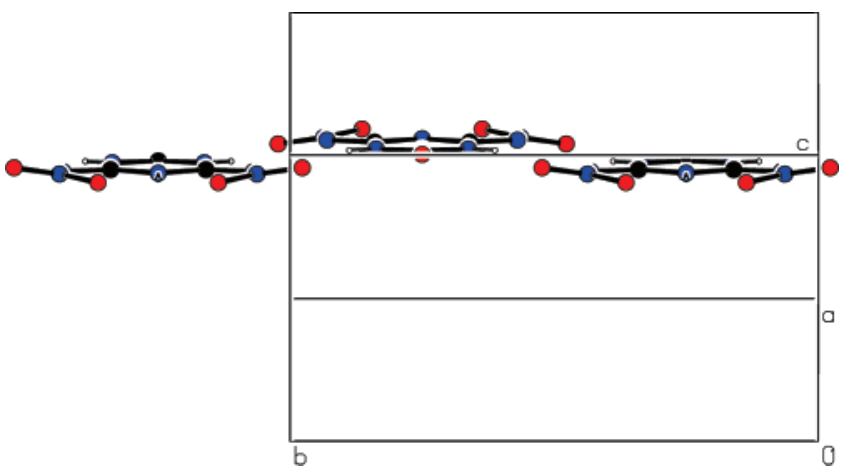

Figure 3. Side view of the H-bonded chains showing the square wave arrangement.

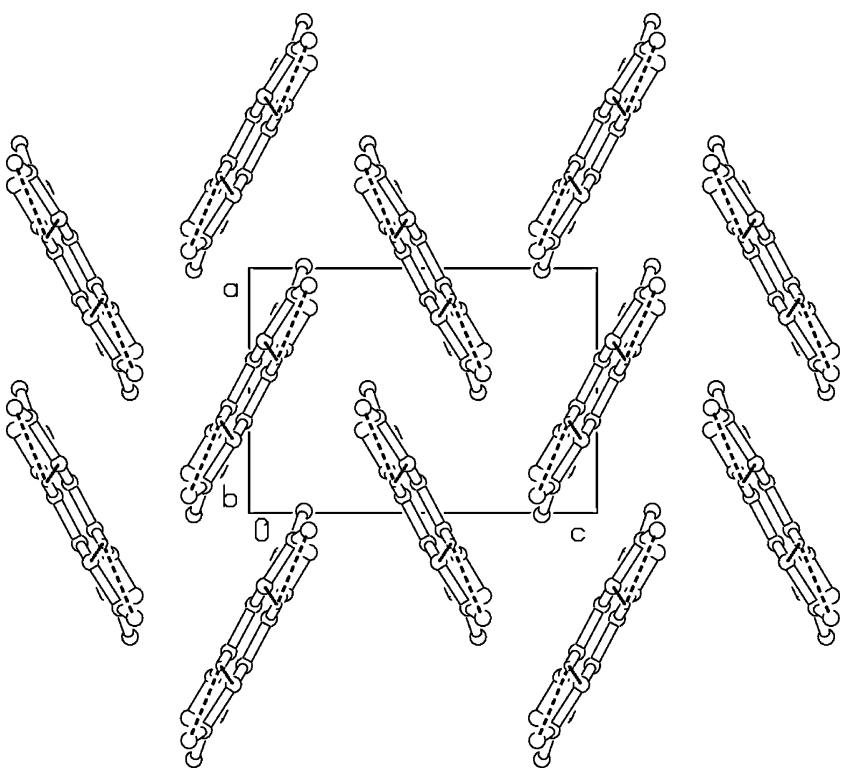

Figure 4. Packing diagram of 4,6-bis(nitroimino)-1,3,5-triazinan-2one projected along the $b$-axis.

isotropic parameters. The crystal data and details concerning data collection and structure refinement are given in Table 2.

The fractional atomic coordinates and equivalent isotropic displacement parameters and other supplementary data have been deposited at the Cambridge Crystallographic Data Center (CCDC 614921).

\section{Results and Discussion}

3.1. X-ray Analysis. The title compound, which the ORTEP diagram is depicted in Figure 1, crystallizes in the space group Pnma with a gliding plane cutting the molecule in two symmetry-related halves. The nitroimine groups are positioned in a syn-syn conformation and the molecule has an approximate $C_{2 v}$ symmetry.

As expected, the heterocyclic ring is very planar, the maximum deviation from the least-squares (LS) plane is 0.026(3) $\AA$ for $\mathrm{C} 2$. The $\mathrm{O} 7$ and N11 also share this plane with deviations $-0.073(3)$ and $0.014(2) \AA$ respectively. The weighted average ring bond distance is $1.3603(12) \AA$ and the weighted average absolute torsion angle is $2.77(13)^{\circ}$. The $\mathrm{C} 6-\mathrm{N} 11-\mathrm{N} 12$ valence angle is $118.21(18)^{\circ}$ and N12 is slightly above the ring LS plane $\left[0.115(2) \AA\right.$ distant]. The $\mathrm{NO}_{2}$ group rotates around the $\mathrm{N} 11-\mathrm{N} 12$ bond by approximately $10^{\circ}$, possibly to favor the H-bond formation as discussed later. The ring plane and the C6 substituent LS plane make an angle of $10.05(11)^{\circ}$.

The molecules are assembled via hydrogen bonds in chains running along the $b$-axis. Every $\mathrm{H}$-atom is involved in bifurcated 
TABLE 3: Comparison of Structural Parameters of the Nitroimine Fragment of DNAM (see Figure 1 for Atom Numbering) with Their Corresponding Counterparts in the Indicated Nitroimines ${ }^{a}$

\begin{tabular}{|c|c|c|c|c|c|c|c|c|c|}
\hline \multirow[b]{2}{*}{ compound } & \multirow[b]{2}{*}{ ref } & \multicolumn{4}{|c|}{ bond length $(\AA)$} & \multicolumn{4}{|c|}{ bond angle (deg) } \\
\hline & & C6-N11 & $\mathrm{N} 11-\mathrm{N} 12$ & $\mathrm{~N} 12-\mathrm{O} 13$ & $\mathrm{~N} 12-\mathrm{O} 15$ & C6-N11-N12 & $\mathrm{N} 11-\mathrm{N} 12-\mathrm{O} 13$ & $\mathrm{~N} 11-\mathrm{N} 12-\mathrm{O} 15$ & $\mathrm{O} 13-\mathrm{N} 12-\mathrm{O} 15$ \\
\hline DNAM & & $1.314(3)$ & $1.382(3)$ & $1.225(2)$ & $1.239(2)$ & $118.21(18)$ & $113.32(18)$ & $123.79(19)$ & $122.88(19)$ \\
\hline NNHT & 21 & $1.360(2)$ & $1.347(2)$ & $1.232(2)$ & $1.243(2)$ & $119.3(2)$ & $114.3(2)$ & $123.8(2)$ & $121.8(2)$ \\
\hline NG & 4 & $1.374(3)$ & $1.331(2)$ & $1.243(2)$ & $1.237(3)$ & $118.7(2)$ & $115.1(2)$ & $124.9(2)$ & $120.0(1)$ \\
\hline MDNG & 6 & $1.333(3)$ & $1.341(3)$ & $1.225(3)$ & $1.229(3)$ & $118.6(2)$ & $115.1(2)$ & $123.9(2)$ & $120.9(2)$ \\
\hline NUDG & 10 & $1.359(3)$ & $1.330(2)$ & $1.226(2)$ & $1.237(2)$ & $119.7(2)$ & $115.9(2)$ & $123.5(2)$ & $120.5(2)$ \\
\hline
\end{tabular}

${ }^{a}$ NNHT: 2-nitrimino-5-nitro-hexahydro-1,3,5-triazine. NG: nitroguanidine. MDNG: methyl-dinitroguanudine; NUDG: 2-nitro-1-ureidoguanidine.

hydrogen bonds (Figure 2). N1 shares H with $\mathrm{O} 13$ and N11 of a neighboring molecule and the $\mathrm{H}$ bonded to $\mathrm{N} 5$ is shared between the symmetry equivalent O14/O15 atoms of the same molecule. As seen in Figure 2, the H-bonds delineate patterns in which rings are the most prominent features. Besides the intramolecular H-bonds, small rings of descriptor R12(4) are formed by $\mathrm{N} 1-\mathrm{H} \cdots \mathrm{O} 13$ and $\mathrm{N} 1-\mathrm{H} \cdots \mathrm{N} 11$, and larger rings of graph descriptor R22(8) are formed by $\mathrm{N} 1-\mathrm{H} \cdots \mathrm{O} 13$, following the notation of Etter. ${ }^{50}$ Infinite chains can also be found, such as $\mathrm{N} 1-\mathrm{H} \cdots \mathrm{O} 13$ design chains with 8 -atom periodicity and $\mathrm{N} 1-$ $\mathrm{H} \cdots \mathrm{N} 11$ with 6-atom periodicity.

As seen in Figure 3, the chains are isolated from each other and within the chain, along the $b$-axis, the molecules congregate in a light square wave arrangement. Along the $a$-axis, the chains stack parallel, but that is not the case along the $c$-axis and a herringbone formation is seen when the structure is projected along the $b$-axis (Figure 4).

The deviation of the ring substituents from planarity in the crystal contrasts with the theoretical results in which a planar structure is predicted by most of the levels of theory applied (see below). The stabilization of the nonplanar form of DNAM in the crystal can be explained by the formation of H-bonds. The costs in energy due to the distortion from planarity should be counterbalanced by the intermolecular H-bonds and the packing effects in the crystal phase. The observed H-bonds also explain the previously reported ${ }^{27-29}$ overall stability of solid DNAM, which is a crucial attribute from the application point of view. The high density and high thermal stability (decomposition without melting above $220^{\circ} \mathrm{C}$ ) of DNAM as well as its low solubility in most common solvents are manifestations of the H-bond network in crystalline DNAM.

The actual bond lengths of $\mathrm{C} 2-\mathrm{O} 7$ [1.379(3) $\mathrm{A}]$ and C6$\mathrm{N} 11[1.314(3) \AA$ ] bonds agree rather well with their formal double bond nature. The remaining $\mathrm{N}-\mathrm{C}$ (ring skeleton) and $\mathrm{N}-\mathrm{N}$ (substituent) bonds have lengths that indicate, more or less, an intermediate character between single and double bonds, which means some degree of $\pi$-conjugated delocalization, typical in other nitroimines.

The number of compounds whose structural characteristics allow a close comparison with the molecule of DNAM as a whole is very scarce. To our best knowledge, 2-nitrimino-5nitro-hexahydro-1,3,5-triazine ${ }^{23}$ is the nearest compound for which structural data recently has been reported ${ }^{21}$ although with substantial differences in the triazine ring. In fact, the geometric parameters of DNAM worthy of comparison with other compounds are restricted to the nitroimine fragment $\left(=\mathrm{N}-\mathrm{NO}_{2}\right)$. Table 3 summarizes such a comparison for some compounds having an intermolecular $\mathrm{H}$-bond in which an O-atom from the nitro group is the acceptor as in DNAM; besides, all but NUDG are characterized also by an extensive network of intermolecular $\mathrm{H}$-bonds. It can be seen from Table 3 that the $\mathrm{N}-\mathrm{O}$ bond lengths referred to as the nitro group are fairly similar in all molecules under comparison. The larger scatter in $\mathrm{C} 6-\mathrm{N} 11$ and N11-
TABLE 4: Summary of Various Geometrical Parameters for the Structures Whose Geometry Was Optimized by MP2 and B3LYP Methods with the Basis Set 6-31-G(d) ${ }^{a}$

\begin{tabular}{|c|c|c|c|c|c|c|c|c|}
\hline & \multicolumn{2}{|c|}{ WB/Å } & \multicolumn{2}{|c|}{ WT/deg } & \multicolumn{2}{|c|}{ LS1/deg } & \multicolumn{2}{|c|}{ LS2/deg } \\
\hline & MP2 & B3LYP & MP2 & B3LYP & MP2 & B3LYP & MP2 & B3LYF \\
\hline NAC1 & 1.359 & 1.358 & 3.30 & 0.63 & 20.88 & 3.82 & 23.80 & 8.21 \\
\hline NAC2 & 1.358 & 1.357 & 3.70 & 0.86 & 32.81 & 11.46 & 22.32 & 3.83 \\
\hline NAC3 & & 1.359 & & 1.14 & & 1.71 & & 31.34 \\
\hline NAC4 & & 1.358 & & 0.95 & & 11.22 & & 38.09 \\
\hline NAC5 & & & & & & & & \\
\hline NAC6 & & & & & & & & \\
\hline NAC7 & 1.361 & 1.359 & 1.08 & 0.73 & 26.10 & 15.23 & 26.10 & 15.23 \\
\hline NAE1 & 1.338 & 1.336 & 2.34 & 0.70 & 25.03 & 7.79 & 25.78 & 8.71 \\
\hline NAE2 & 1.337 & 1.335 & 2.70 & 0.19 & 27.28 & 3.12 & 23.58 & 1.21 \\
\hline NAE3 & 1.338 & 1.336 & 2.54 & 0.41 & 27.01 & 7.06 & 22.57 & 1.03 \\
\hline NAE4 & 1.337 & 1.336 & 3.18 & 0.52 & 29.11 & 4.48 & 28.66 & 7.53 \\
\hline NIC1 & 1.378 & 1.379 & 0.00 & 0.00 & 0.00 & 0.00 & 0.00 & 0.00 \\
\hline IC2 & 1.378 & & 0.00 & 0.00 & 0.00 & 0.00 & 0.00 & 0.00 \\
\hline NIC3 & 1.379 & 1.380 & 0.00 & 0.00 & 0.00 & 0.00 & 0.00 & 0.00 \\
\hline NIE1 & 1.361 & 1.360 & 1.25 & 0.00 & 1.37 & 0.00 & 13.12 & 0.00 \\
\hline NIE2 & 1.363 & 1.363 & 0.00 & 0.00 & 0.00 & 0.00 & 90.00 & 90.00 \\
\hline NIE3 & 1.363 & 1.363 & 0.00 & 0.00 & 0.00 & 0.00 & 90.00 & 90.00 \\
\hline NIE4 & 1.363 & 1.362 & 3.72 & 0.00 & 8.13 & 0.00 & 40.48 & 0.00 \\
\hline
\end{tabular}

${ }^{a} \mathrm{WB}$ : weighted average ring bond distance. WT: weighted average absolute torsion angle. LS1: angle between the ring LS plane and the C4 substituent LS plane. LS2: angle between the ring LS plane and the C6 substituent LS plane.

N12 bond lengths can be explained by differences in the nonnitroimine skeleton of the compared molecular structures as well as by differences in crystal-packing effects. These also can justify the observed departures in the valence angles from the respective DNAM counterparts.

3.2. Computational Results. 3.2.1. Comparison of Method (MP2 versus DFT) and Basis Set Dependencies (DFT). As mentioned, the comparison of B3LYP (DFT) and MP2 (ab initio) results was made possible only for the basis set 6-31G(d) because of limitations in the computational resources.

Geometries. In both MP2 and DFT methods, most of the optimized structures exhibit $C_{1}$ symmetries. The exceptions are the $C_{s}$ symmetry for NIC1, NIC2, NIC3, and NIE1. In the MP2 method, the structures NAC3 and NAC4 converge to NAC1 and $\mathrm{NAC} 2$, respectively, whereas in both MP2 and B3LYP the structures NAC5 and NAC6 converge to NAC7.

Table 4 shows some pertinent geometrical parameters to facilitate the comparison of the optimization results from the two methods. Emphasis is given to the triazine ring and to the twisting, when existing, exhibited by the substituents (nitramine or nitroimine fragments) related to the ring.

As expected, the ring differs from the regular hexagonal geometry due to the effect of the substituents. The bond lengths calculated from both methods are very similar in all structures. The diferences are within $0.01 \AA$ for almost all bonds (with a few exceptions in which differences are within $0.02 \AA$ ) in all tautomeric series (NAC, NAE, NIC, and NIE). 


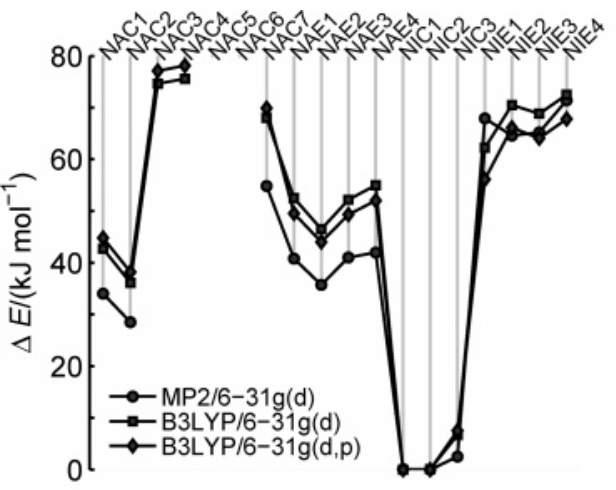

(a)

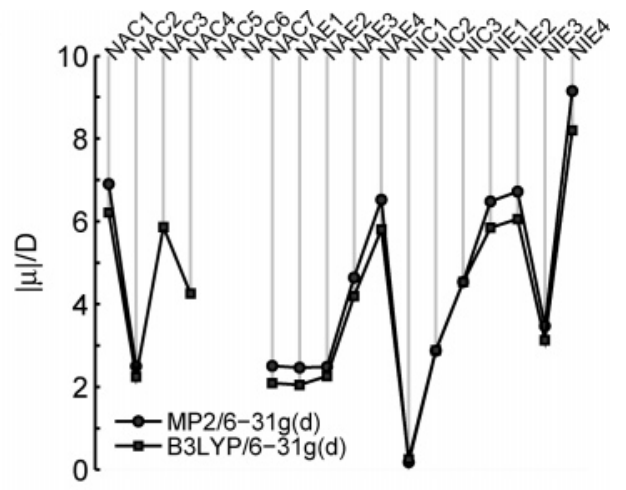

(b)

Figure 5. Comparison of (a) relative energies and (b) molecular dipoles, when computed by the models MP2/6-31G(d) and B3LYP/6-31G(d).

TABLE 5: Total and Relative Energies (after ZPE Correction) and Molecular Dipole for the Most Stable Tautomers/ Conformers Studied, Calculated by the Indicated Levels of Theory

\begin{tabular}{|c|c|c|c|c|c|c|}
\hline & \multicolumn{2}{|c|}{ MP2/6-31G(d) } & \multicolumn{2}{|c|}{ B3LYP/6-31G(d) } & \multicolumn{2}{|c|}{ B3LYP/6-311++G(3df,3pd) } \\
\hline & $E_{\mathrm{el}} / \mathrm{Ha}$ & $\left(E_{\mathrm{el}}+\mathrm{ZPE}\right) / \mathrm{Ha}$ & $E_{\mathrm{el}} / \mathrm{Ha}$ & $\left(E_{\mathrm{el}}+\mathrm{ZPE}\right) / \mathrm{Ha}$ & $E_{\mathrm{el}} / \mathrm{Ha}$ & $\left(E_{\mathrm{el}}+\mathrm{ZPE}\right) / \mathrm{Ha}$ \\
\hline NIC1 & -872.970570 & -872.860644 & -875.296643 & -875.187551 & -875.631397 & -875.522893 \\
\hline NIC2 & -872.970571 & -872.860665 & -875.296565 & -875.187523 & -875.631296 & -875.522829 \\
\hline \multirow[t]{2}{*}{ NIC3 } & -872.969484 & -872.859715 & -875.293860 & -875.184992 & -875.628505 & -875.520197 \\
\hline & $\Delta E /\left(\mathrm{kJ} \mathrm{mol}^{-1}\right)$ & $|\mu| / \mathrm{D}$ & $\Delta E /\left(\mathrm{kJ} \mathrm{mol}^{-1}\right)$ & $|\mu| / \mathrm{D}$ & $\Delta E /\left(\mathrm{kJ} \mathrm{mol}^{-1}\right)$ & $|\mu| / \mathrm{D}$ \\
\hline NIC1 & 0.1 & 0.179 & 0.0 & 0.248 & 0.0 & 0.115 \\
\hline NIC2 & 0.0 & 2.870 & 0.1 & 2.885 & 0.2 & 2.819 \\
\hline NIC3 & 2.5 & 4.535 & 6.7 & 4.538 & 7.1 & 4.502 \\
\hline
\end{tabular}

For structures with symmetry other than $C_{s}$, the heterocycle ring is predicted to be essentially planar by the B3LYP method, whereas in MP2 calculations some departures from the perfect planarity were found (see weighted average absolute torsion angle (WT) values in Table 4). The nitramine or nitroimine substituents are distorted in relation to the ring plan. As can be seen from Table 4, MP2 method systematically predicts higher distortions when compared with the B3LYP method. This pattern is common to most structures with $C_{1}$ symmetry, but for structures NIE2 and NIE3 both methods predicted a significant twisting $\left(90^{\circ}\right)$ of the C6 substituent with respect to the triazine ring.

The NIC series correspond to the most stable tautomers (see below). The geometries predicted by both methods are in very close agreement (see Supporting Information; geometries and energies of other structures of DNAM studied within the theoretical framework considered in this work are available upon request). The differences in all the bonds are within $0.01 \AA$, except for the NO bonds (nitro group), which are within 0.02 $\AA$. A very good agreement is observed also in bond angles in which the discrepancies are not more than $1^{\circ}$ with the exception of only few cases.

Energetics. The energies (after zero-point energy (ZPE) correction) relative to the most stable tautomer found in each method and molecular dipoles are compared in Figure 5. Besides the differences in results from MP2 and B3LYP, Figure 5a also allows us to compare the relative energies computed with the B3LYP method when the basis $6-31 G(d)$ is replaced by the $6-31 G(d, p)$. The general trend among the different structures is essentially identical. Globally, there is a closer agreement between the relative energies from the two methods in the case of the nitroimine forms (NIC and NIE series). DFT systematically predicts higher values of $\Delta E$ when compared with those obtained from MP2, the NIE1 tautomer being the unique exception. Figure $5 \mathrm{~b}$ also shows that no remarkable differences in the whole tendency are observed when comparing the results from B3LYP/6-31G(d) and B3LYP/6-31G(d,p) levels of theory. As seen in Figure 5b, B3LYP calculated molecular dipoles are close to those calculated with MP2.

Besides the NIC set, the NAC2 tautomer is predicted as the most stable. However, NAC2 is about $26 \mathrm{~kJ} \mathrm{~mol}^{-1}$ (MP2) or $29 \mathrm{~kJ} \mathrm{~mol}^{-1}$ (B3LYP) less stable than NIC3 (the less stable of the NIC forms). Thus, in the gas phase, structures other than NIC1, NIC2, and possibly NIC3 cannot exist with virtually any probability. Although there is theoretical interest in at least some of the remaining structures, our attention will be focused only in the three most stable tautomers, particularly to NIC3, whose occurrence in the crystal was proven by X-ray analysis.

Bearing in mind that DNAM has never been studied theoretically, we decided to check if the results from the smaller basis set deviate significantly from those of larger basis sets. The level of theory B3LYP/6-311++G(3df,3pd) was employed to obtain full geometry optimizations and total energies for the most stable tautomers (the NIC set). The results (energies and molecular dipoles) are shown in Table 5 together with those obtained at the levels of theory MP2/6-31G(d) and B3LYP/6$31 \mathrm{G}(\mathrm{d})$ for an easier comparison.

The predictions from the two methods (MP2 and B3LYP) for $\mathrm{NIC} 1$ and $\mathrm{NIC} 2$ are quite similar in terms of relative energies and molecular dipoles. A difference in $\Delta E$ of ca. $4 \mathrm{~kJ} \mathrm{~mol}^{-1}$ between B3LYP and MP2 calculations is predicted for NIC3. As it can be seen from Table 5, within the same method and ongoing from the smaller [B3LYP/6-31G(d)] to the larger level of theory [B3LYP/6-311++G(3df,3pd)], the computed relative energies and molecular dipole moments for the NIC series do not change significantly. A common characteristic to the three conformers is the occurrence of intramolecular hydrogen bonds as a stabilizing factor. However, the differences with respect to the molecular dipole are remarkable, being a possible compensating factor for energy disadvantages. Because of the higher molecular dipole value exhibited by NIC3, this form is expected to be more stabilized in polar environments such as polar crystal 
TABLE 6: Pertinent Geometrical Parameters for Structure NIC3 Optimized at the Level of Theory B3LYP/aug-cc-pVQZ and Correspondent Values from X-ray Analysis

\begin{tabular}{|c|c|c|c|c|c|c|c|c|}
\hline bond $(\AA)$ & calc & $\exp$ & angle (deg) & calc & $\exp$ & dihedral (deg) & calc & $\exp$ \\
\hline $\mathrm{N} 1-\mathrm{C} 2$ & 1.386 & $1.379(3)$ & $\mathrm{C} 2-\mathrm{N} 1-\mathrm{C} 6$ & 125.7 & $124.7(2)$ & $\mathrm{N} 1-\mathrm{C} 2-\mathrm{N} 3-\mathrm{C} 4$ & 0 & $4.9(4)$ \\
\hline $\mathrm{N} 1-\mathrm{C} 6$ & 1.370 & $1.348(3)$ & $\mathrm{C} 2-\mathrm{N} 1-\mathrm{H} 18$ & 117.2 & 116.1(18) & $\mathrm{O} 7-\mathrm{C} 2-\mathrm{N} 3-\mathrm{C} 4$ & 180 & $-176.4(3)$ \\
\hline $\mathrm{N} 1-\mathrm{H} 18$ & 1.010 & $0.78(3)$ & $\mathrm{C} 6-\mathrm{N} 1-\mathrm{H} 18$ & 117.0 & $119.1(18)$ & $\mathrm{C} 2-\mathrm{N} 3-\mathrm{C} 4-\mathrm{N} 5$ & 0 & $-2.5(3)$ \\
\hline $\mathrm{C} 2-\mathrm{O} 7$ & 1.200 & $1.201(4)$ & $\mathrm{N} 1-\mathrm{C} 2-\mathrm{N} 3$ & 112.8 & $113.8(3)$ & $\mathrm{C} 2-\mathrm{N} 3-\mathrm{C} 4-\mathrm{N} 8$ & 180 & $178.3(2)$ \\
\hline $\mathrm{C} 4-\mathrm{N} 5$ & 1.366 & $1.353(2)$ & $\mathrm{N} 1-\mathrm{C} 2-\mathrm{O} 7$ & 123.6 & $123.10(15)$ & $\mathrm{N} 3-\mathrm{C} 4-\mathrm{N} 5-\mathrm{C} 6$ & 0 & $-0.3(4)$ \\
\hline N5-H17 & 1.023 & $0.84(4)$ & $\mathrm{C} 4-\mathrm{N} 5-\mathrm{C} 6$ & 124.1 & $124.1(3)$ & $\mathrm{N} 8-\mathrm{C} 4-\mathrm{N} 5-\mathrm{C} 6$ & -180 & $178.72(15)$ \\
\hline C6-N11 & 1.300 & $1.314(3)$ & $\mathrm{C} 6-\mathrm{N} 5-\mathrm{H} 17$ & 118.0 & $117.89(16)$ & $\mathrm{N} 3-\mathrm{C} 4-\mathrm{N} 8-\mathrm{N} 9$ & 180 & $174.50(17)$ \\
\hline $\mathrm{N} 11-\mathrm{N} 12$ & 1.402 & $1.382(3)$ & N1-C6-N5 & 115.8 & $116.2(2)$ & $\mathrm{N} 5-\mathrm{C} 4-\mathrm{N} 8-\mathrm{N} 9$ & 0 & $-4.6(3)$ \\
\hline $\mathrm{N} 12-\mathrm{O} 13$ & 1.206 & $1.225(2)$ & $\mathrm{N} 1-\mathrm{C} 6-\mathrm{N} 11$ & 114.7 & $116.31(19)$ & $\mathrm{C} 4-\mathrm{N} 8-\mathrm{N} 9-\mathrm{O} 10$ & 180 & $-169.68(18)$ \\
\hline \multirow[t]{5}{*}{$\mathrm{N} 12-\mathrm{O} 15$} & 1.233 & $1.239(2)$ & N5-C6-N11 & 129.5 & $127.5(2)$ & C4-N8-N9-O14 & 0 & $11.5(3)$ \\
\hline & & & C6-N11-N12 & 119.8 & $118.21(18)$ & & & \\
\hline & & & $\mathrm{N} 11-\mathrm{N} 12-\mathrm{O} 13$ & 114.2 & $113.32(18)$ & & & \\
\hline & & & $\mathrm{N} 11-\mathrm{N} 12-\mathrm{O} 15$ & 121.0 & $123.79(19)$ & & & \\
\hline & & & $\mathrm{O} 13-\mathrm{N} 12-\mathrm{O} 15$ & 124.9 & $122.88(19)$ & & & \\
\hline
\end{tabular}

fields. This constitutes a plausible factor underlying the occurrence of the NIC3 form in the crystal.

Basis Set Dependencies from DFT Calculations. Extensive calculations on the NIC3 form using the B3LYP functional have been performed. A large range of basis sets has been considered, from 6-31G(d,p) to 6-311++G(3df,3pd) Pople's type as well as the aug-cc-pVQZ Dunning's basis set (detailed results in Supporting Information). Table 6 presents relevant geometrical parameters computed at the highest level of theory employed in this work, B3LYP/aug-cc-pVQZ, together with the correspondent values from X-ray analysis.

The agreement between computed and experimentally observed bond lengths and bond angles is noteworthy when taking into account that we are comparing values computed for the free molecule in the gas phase with measured values in a crystal environment. The effect of such an environment is much more pronounced in dihedral angles in which deviations of the calculated from those derived from X-ray analysis are noticeable, mainly because of the distortions exhibited by the nitroimine substituents with relation to the ring.

3.2.2. H-bonding and Related Items. We now turn to X-ray analysis to consider the problem related to the uncertainty in locating the hydrogen atom positions by X-ray diffraction. As it can be seen from Table 6, pronounced differences exist between the predicted and the experimental values for the bond lengths in which $\mathrm{H}$ atoms are involved (it is worth mentioning that values from X-ray analysis for the $\mathrm{NH}$ bond lengths were not corrected/normalized). A question that can be raised regarding this topic is whether or not theoretical calculations can be used to predict the $\mathrm{NH}$ bond lengths in crystalline DNAM.

As mentioned before, in the crystal every hydrogen participates in three-center $\mathrm{H}$-bonds. In each molecule, the $\mathrm{N} 1-\mathrm{H}$ (or $\mathrm{N} 3-\mathrm{H})$ moiety is involved in a bifurcated intermolecular $\mathrm{H}$-bond whose acceptors are of a different type, whereas the $\mathrm{N} 5-\mathrm{H}$ fragment participates in a symmetric bifurcated intramolecular H-bond with acceptors of the same kind. The crystal lattice of DNAM suggests that the intermolecular H-bonds in which each molecular entity is involved would be more directly influenced by the crystal surroundings than the intramolecular H-bonds. Correspondingly, similar relative influences would be expected over $\mathrm{N} 1-\mathrm{H}$ (or $\mathrm{N} 3-\mathrm{H}$ ) and $\mathrm{N} 5-\mathrm{H}$ bond lengths.

To simulate the interaction of each molecule of DNAM within the chains formed via hydrogen bonds (see Figures 2 and 3), and thus to evaluate the influence of the surrounding chemical environment (along stacks) on the $\mathrm{NH}$ bond lengths (mainly for $\mathrm{N} 1-\mathrm{H}$ or $\mathrm{N} 3-\mathrm{H}$ bonds), we took a simplified model based on a trimer of DNAM as shown in Figure 6. The optimization of the cluster was carried out by imposing planarity $\left(C_{s}\right.$ symmetry) at the level of theory B3LYP/6-31+G(d,p). Frequency calculation at the same level of theory revealed no imaginary frequencies, indicating that an optimal geometry at this level of approximation was found for the trimer that was not disturbed by the surrounding environment.

As depicted in Figure 7, ongoing from the isolated molecule [for which values are concerned with computations also at the level B3LYP/6-31+G(d,p)] to the trimer (for which the comparisons are referred to the central molecule), a lengthening of ca. $0.009 \AA$ is predicted for N1-C2 and C6-N11 bonds. The lengthening is more pronounced for $\mathrm{N} 12-\mathrm{O} 13$ and $\mathrm{N} 1-\mathrm{H}$ bonds, whose values found are $0.018 \AA$ and $0.019 \AA$, respectively. All the remaining bonds appear to be shortened: 0.027 $\AA$ for $\mathrm{N} 11-\mathrm{N} 12,0.014 \AA$ for N1-C6, $0.005 \AA$ for $\mathrm{C} 2-\mathrm{O} 7$, $0.004 \AA$ for $\mathrm{N} 12-\mathrm{O} 15$, and $0.001 \AA$ for $\mathrm{C} 4-\mathrm{N} 5$ and $\mathrm{N} 5-\mathrm{H}$. For bond angles, the differences between the results for monomer and those from the trimer model are within a $1^{\circ}$ interval for all cases other than those based on N5-C6-N11, $\mathrm{N} 11-\mathrm{N} 12-\mathrm{O} 15$, and $\mathrm{O} 13-\mathrm{N} 12-\mathrm{O} 15$ centers in which a difference less than ca. $2^{\circ}$ was computed.

The predicted elongation of the $\mathrm{N} 1-\mathrm{H}$ bond because of its participation in intermolecular $\mathrm{H}$-bonds is consistent with what has been observed in many types of $\mathrm{H}$-bonds involving either $\mathrm{O}$ or $\mathrm{N}$ atoms as acceptors. ${ }^{51} \mathrm{On}$ the other hand, the apparently contradictory slight shortening of the intramolecular $\mathrm{N} 5-\mathrm{H}$ bonds can be rationalized by invoking the influence of the intermolecular H-bonds on the covalent geometry of the participating molecules. This stands also for the other geometric changes.

Table 7 summarizes the hydrogen-bonding parameters obtained from the theoretical model and also from X-ray analysis. As it can be seen, the intermolecular $\mathrm{H} \cdots \mathrm{O}$ length is predicted to be $1.977 \AA$, whereas the computed intramolecular $\mathrm{H} \cdot . \mathrm{O}$ distance is $1.907 \AA$. These are values far below the sum of the van der Waals radii (that is, $2.72 \AA^{52}$ or $2.65 \AA^{53}$ for the pair $\mathrm{H} \cdots \mathrm{O}$ ). On the other hand, the calculated intermolecular $\mathrm{H} \cdots$ $\mathrm{N}$ length is $2.877 \AA$, which is higher than the sum of the van

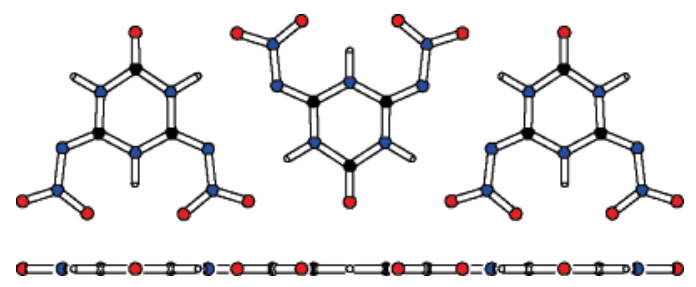

Figure 6. Different views of the model based on a trimer of DNAM (see also Figures 2 and 3). 

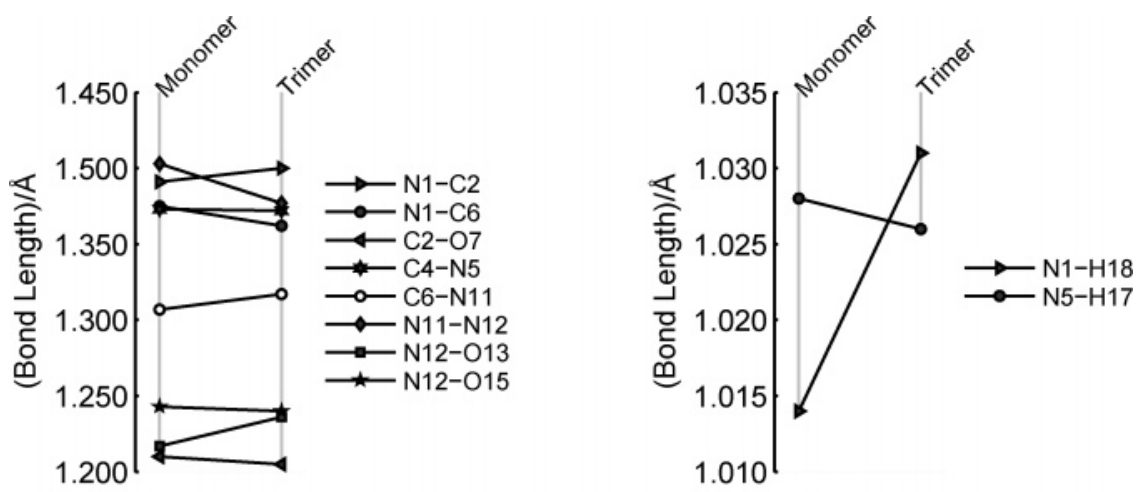

(a)

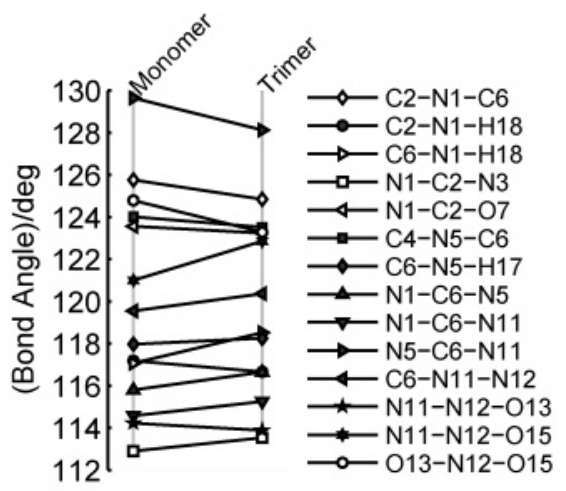

(b)

Figure 7. Comparison of (a) bond lengths and (b) bond angles for an isolated molecule and for a trimer of NIC3, computed at the level of theory B3LYP/6-31+G(d,p). Values for the trimer correspond to the central molecule.

TABLE 7: Hydrogen-Bonding Parameters from X-ray Analysis and from Theoretical Calculations for a Trimer of NIC3 at the Level of Approximation B3LYP/6-31 $+\mathbf{G}(\mathbf{d}, \mathbf{p})^{a}$

\begin{tabular}{|c|c|c|c|c|c|c|c|c|}
\hline \multirow[b]{2}{*}{$\mathrm{D}-\mathrm{H} \cdots \mathrm{A}$} & \multicolumn{2}{|c|}{$\begin{array}{c}\mathrm{D}-\mathrm{H} \\
(\AA)\end{array}$} & \multicolumn{2}{|c|}{$\begin{array}{c}\mathrm{H} \cdots \mathrm{A} \\
(\AA)\end{array}$} & \multicolumn{2}{|c|}{$\begin{array}{c}\mathrm{D} \cdots \mathrm{A} \\
(\AA)\end{array}$} & \multicolumn{2}{|c|}{$\begin{array}{c}\mathrm{D}-\mathrm{H} \cdots \mathrm{A} \\
(\mathrm{deg})\end{array}$} \\
\hline & calc & $\exp$ & calc & $\exp$ & calc & $\exp$ & calc & $\exp$ \\
\hline $\mathrm{N} 1-\mathrm{H} \cdots \mathrm{O}$ & 1.030 & $0.79(3)$ & 1.977 & $2.37(3)$ & 2.996 & $3.074(3)$ & 169.21 & $150(2)$ \\
\hline $\mathrm{N} 1-\mathrm{H} \cdots \mathrm{N}$ & 1.030 & $0.79(3)$ & 2.877 & $2.48(3)$ & 3.736 & $3.191(3)$ & 141.24 & $153(2)$ \\
\hline $\mathrm{N} 5-\mathrm{H} \cdots \mathrm{O}$ & 1.027 & $0.84(4)$ & 1.907 & $1.94(3)$ & 2.600 & $2.547(3)$ & 121.92 & $128.5(10)$ \\
\hline
\end{tabular}

${ }^{a}$ For calculated parameters, $\mathrm{H}$ and $\mathrm{D}$ are referred to as the central molecule in the trimer.

der Waals radii (that is, $2.75 \AA^{52}$ or $2.70 \AA^{53}$ ). Another important $\mathrm{H}$-bond characteristic is the directionality toward the acceptor (the favored geometrical arrangement of the three atoms $\mathrm{D}-\mathrm{H} \cdots \mathrm{A}$ is linear). The $\mathrm{N} 1-\mathrm{H} \cdots \mathrm{O}$ angle in the trimer is $169.21^{\circ}$, whereas the $\mathrm{N} 1-\mathrm{H} \cdots \mathrm{N}$ angle is $141.24^{\circ}$, thus the first angle being closer to an optimal hydrogen bond geometry.

As it can be observed from Table 7, there are appreciable differences between the computed intermolecular $\mathrm{H}$-bond parameters and those obtained from X-ray data. This is particularly true for the parameters directly related to the positions of the $\mathrm{H}$ atom, namely the (intermolecular) $\mathrm{H} \cdots \mathrm{O}$ and $\mathrm{H} \cdots \mathrm{N}$ lengths. Even when the comparison is restricted to donor-acceptor pairs, it can be observed that a fairly good agreement in $\mathrm{N} 1 \cdots \mathrm{O}$ length contrasts with a remarkable discrepancy in $\mathrm{N} 1 \cdots \mathrm{N}$ distance. It is worth mentioning, however, that the actual and the modeled relative position of each contiguous molecule differ considerably (this also can be checked in Table 7 by comparing the calculated and experimental values of $\mathrm{N} 1-\mathrm{H} \cdots \mathrm{O}$ and $\mathrm{N} 1-\mathrm{H} \cdots \mathrm{N}$ angles). Furthermore, the condition in which the four atoms involved in bifurcated $\mathrm{H}$-bonds are typically in or close to a plane ${ }^{54}$ is observed in both cases, but only in the theoretical model are the four atoms strictly in a plane.

In light of the previous discussion, it is true that any conclusions from the theoretical calculations should be drawn cautiously. Nevertheless, despite the simplicity of the model considered, which does not account for other pertinent crystalpacking effects such as the intermolecular contacts between stacks and other environmental effects, it clearly suggests that the intramolecular $\mathrm{H}$-bond and thus the $\mathrm{N} 5-\mathrm{H}$ bond length is much less prone to be influenced by the molecular neighboring when compared with intermolecular bonds. In fact, the noticeable differences pointed out with respect to intermolecular $\mathrm{H}$-bonds are considerably less pronounced in the case of their intramolecular counterparts. Thus, it seems reasonable to accept the value $1.010 \AA$ (obtained from B3LYP/aug-cc-pVQZ calculations) as a plausible good approximation for the intramolecular $\mathrm{N} 5-\mathrm{H}$ bond in the crystalline DNAM. Besides, this figure agrees very well with the value $1.009 \AA$, which is the accepted standard for the $\mathrm{N}-\mathrm{H}$ bond length based on average neutron-determined internuclear distances. ${ }^{51}$ Coincidently (or not), the value $1.023 \AA$ (also calculated by means of the B3LYP/ 
aug-cc-pVQZ model chemistry) for the N1-H bond is reasonably close to that standard as well. However, considering the reasons invoked above, its attribution to the crystal state is more doubtful and therefore more demanding for new evidence.

\section{Conclusion}

Structural investigations of the title compound, 4,6-bis(nitroimino)-1,3,5-triazinan-2-one (DNAM), have been performed both theoretically by means of quantum mechanical calculations (ab initio and mainly DFT methods) and experimentally through an X-ray crystallographic study. A collection of new data on DNAM is now available.

A total of 18 different possible tautomers were studied theoretically. These included different conformers within a diverse tautomer series, such as those with nitroamine and nitrimine moieties in either their enolic or keto forms. It was found that in the gas phase, the nitroimine (keto) tautomers are computed to be considerably more stable than the nitramine tautomers. In the group of the three most probable nitroimine forms, as predicted by both MP2 and DFT methods, special attention was given to 4,6-bis(nitroimino)-1,3,5-triazinan-2-one (NIC3) because this was the molecular form proved to exist in the crystal. The comprehensive DFT study [16 Pople kind basis sets, from $6-31 \mathrm{G}(\mathrm{d})$ to $6-311++\mathrm{G}(3 \mathrm{df}, 3 \mathrm{dp})$ and the aug-ccpVQZ Dunning basis set] that was focused on the geometrical parameters of NIC3, showed that from the 6-311G(d,p) basis set to the higher sized basis functions, the bond lengths converged within $0.01 \AA$, whereas the valence angles were found to be within a $1 \AA$ interval for all the range of basis functions studied.

The X-ray diffraction analysis shows that crystals are orthorhombic, space group Pnma. The molecular conformation in the crystal, fairly well reproduced by the theoretical calculations, seems to be strongly correlated with the intra and intermolecular bifurcated hydrogen-bonded network, which explains the reported overall stability of solid DNAM.

Acknowledgment. We acknowledge the provision of time on the Small Molecule Crystallography Service at the CCLRC Daresbury Laboratory via support by the European Community-Research Infrastructure Action under the FP6 "Structuring the European Research Area" Programme (through the Integrated Infrastructure Initiative "Integrating Activity on Synchrotron and Free Electron Laser Science".

Acknowledgment. P.N.S. thanks Professor Rui Fausto and Dr. Igor Reva from the Chemistry Department for their support in computational issues.

Supporting Information Available: Tables S01 to S03, which list optimized geometries for structures NIC1, NIC2, and NIC3 obtained by the methods MP2/6-31G(d) and B3LYP/631G(d). Table S04, which lists optimized geometries for structures NIC1, NIC2, and NIC3 obtained at the level of theory B3LYP/6-311++G(3df,3pd). Table S05 to S07, which list geometrical parameters for structure NIC3 calculated with the B3LYP method and the Pople's type from 6-31G(d,p) to $6-311++\mathrm{G}(3 \mathrm{df}, 3 \mathrm{pd})$ the aug-cc-pVQZ Dunning's basis set. This material is available free of charge via the Internet at http:// pubs.acs.org.

\section{References and Notes}

(1) Fried, L.; Manaa, M.; Pagoria, P.; Simpson, R. Annu. Rev. Mater. Res. 2001, 31, 291-321.
(2) Shastin, A.; Godovikova, T.; Korsunskii, B. Russ. Chem. Rev. 2003 , 72,279

(3) Raczyńska, E.; Kosińska, W.; Ośmiałowski, B.; Gawinecki, R. Chem. Rev. 2005, 105, 3561-3612.

(4) Murmann, R.; Glaser, R.; Barnes, C. J. Chem. Crystallogr. 2005, 35,317 .

(5) Türker, L. THEOCHEM 2004, 681, 177.

(6) Vasiliev, A.; Astakhov, A.; Molokeev, M.; Kruglyakova, L.; Stepanov, R. J. Struct. Chem. 2004, 45, 532.

(7) Vasiliev, A.; Astachov, A.; Molokeev, M.; Kruglyakova, L.; Stepanov, R. Acta Crystallogr., Sect. E 2003, 59, 193.

(8) Vasiliev, A.; Astachov, A.; Molokeev, M.; Kruglyakova, L.; Stepanov, R. Acta Crystallogr., Sect. C 2003, 59, 550.

(9) Astrat'yev, A.; Dashko, D.; Kuznetsov, L. Russ. J. Org. Chem. $\mathbf{2 0 0 3}, 31,501$.

(10) Astakhov, A. M.; Vasil'ev, A.; Molokeev, M.; Kekin, Y.; Kruglyakova, L.; Stepanov, R. J. Struct. Chem. 2003, 44, 326.

(11) Vasiliev, A.; Astachov, A.; Nefedov, A.; Kruglyakova, L.; Stepanov, R. Acta Crystallogr., Sect. C 2001, 57, 625.

(12) Bracuti, A. J. Chem. Crystallogr. 1999, 29, 671-676.

(13) Rice, S.; Cheng, M.; Cramer, R.; Mandel, M.; Mower, H.; Seff, K. J. Am. Chem. Soc. 1984, 106, 239.

(14) Oszust, J.; Baran, J.; Pietraszko, A.; Drozd, M.; Talik, Z. Spectrochim. Acta, Part A 2005, 62, 773.

(15) Laihia, K.; Kolehmainen, E.; Virtanen, E.; Nissinen, M.; Puszko, A.; Talik, Z. Magn. Reson. Chem. 2003, 41, 721.

(16) Kyziol, J.; Broda, M.; Zaleski, J.; Daszkiewicz, Z. J. Mol. Struct. 2002, 605, 157 .

(17) Szemik-Hojniak, A.; Glowiak, T.; Deperasinska, I.; Puszko, A. Can. J. Chem. 2002, 80, 1242 .

(18) Szemik-Hojniak, A.; Glowiak, T.; Deperasinska, I.; Puszko, A. J. Mol. Struct. 2001, 597, 279.

(19) Daszkiewicz, Z.; Kyziol, J. B.; Zaleski, J. J. Mol. Struct. 1999, 513,69 .

(20) Gawinecki, R.; Raczynska, E. D.; Rasalla, D.; Styrcz, S. Tetrahedron 1997, 53, 17211.

(21) Bracuti, A. J. Chem. Crystallogr. 2004, 34, 135-140.

(22) Astakhov, A.; Vasil'ev, A.; Gelemurzina, I.; Sokolenko, V.; Kruglyakova, L.; Stepanov, R. Russ. J. Org. Chem. 2003, 39, 120.

(23) Cliff, M.; Dagley, I.; Parker, R.; Walker, G. Propellants, Explos. Pyrotech. 1998, 23, 179-181.

(24) Moskalenko, G.; Shkurko, O. Chem. Heterocycl. Compd. 1997, 33 , 843.

(25) Daszkiewicz, Z.; Spaleniak, G.; Kyziol, J. B. J. Phys. Org. Chem. 2002, 15, 115 .

(26) Atkinson, E. R. J. Am. Chem. Soc. 1951, 73, 4443.

(27) Simões, P.; Pedroso, L.; Carvalheira, P.; Campos, J.; Portugal, A. Propellants, Explos., Pyrotech. 2001, 26, 273.

(28) Simões, P.; Pedroso, L.; Plaksin, I.; Campos, J.; Portugal, A. Propellants, Explos., Pyrotech. 2001, 26, 278. 95.

(30) Frisch, M. J.; Trucks, G. W.; Schlegel, H. B.; Scuseria, G. E.; Robb, M. A.; Cheeseman, J. R.; Zakrzewski, V. G.; Montgomery, J. A. Jr.; Stratmann, R. E.; Burant, J. C.; Dapprich, S.; Millam, J. M.; Daniels, A D.; Kudin, K. N.; Strain, M. C.; Farkas, O.; Tomasi, J.; Barone, V.; Cossi, M.; Cammi, R.; Mennucci, B.; Pomelli, C.; Adamo, C.; Clifford, S.; Ochterski, J.; Petersson, G. A.; Ayala, P. Y.; Cui, Q.; Morokuma, K.; Malick, D. K.; Rabuck, A. D.; Raghavachari, K.; Foresman, J. B.; Cioslowski, J.; Ortiz, J. V.; Baboul, A. G.; Stefanov, B. B.; Liu, G.; Liashenko, A.; Piskorz, P.; Komaromi, I.; Gomperts, R.; Martin, R. L.; Fox, D. J.; Keith, T.; AlLaham, M. A.; Peng, C. Y.; Nanayakkara, A.; Gonzalez, C.; Challacombe, M.; Gill, P. M. W.; Johnson, B. G.; Chen, W.; Wong, M. W.; Andres, J. L.; Head-Gordon, M.; Replogle, E. S.; Pople, J. A. Gaussian 98 (Revision A.9), Gaussian, Inc., Pittsburgh, PA, 1998.

(31) Parr, R.; Wang, W. Density-Functional Theory of Atoms and Molecules; Oxford University Press: New York, 1994.

(32) Neumann, R.; Nobes, R.; Handy, N. Mol. Phys. 1996, 87, 1.

(33) Møller, C.; Plesset, M. Phys. Rev. 1934, 46, 618.

(34) Becke, A. D. Phys. Rev. A 1988, 38, 3098.

(35) Lee, C.; Yang, W.; Parr, R. G. Phys. Rev. B 1988, 37, 785.

(36) Becke, A. D. J. Chem. Phys. 1993, 98, 5648.

(37) Hariharan, P.; Pople, J. Chem. Phys. Lett. 1972, 66, 217.

(38) Hehre, W. J.; Ditchfield, R.; Pople, J. A. J. Chem. Phys. 1972, 56, 2257.

(39) Binkley, J.; Pople, J. Int. J. Quantum Chem. 1975, 9, 229.

(40) Krishnan, R.; Frisch, M.; Pople, J. J. Chem. Phys. 1980, 72, 4244.

(41) Frisch, M.; Pople, J.; Binkley, J. J. Chem. Phys. 1984, 80, 3265.

(42) Dunning, T., Jr. J. Chem. Phys. 1989, 90, 1007.

(43) Peng, C.; Ayala, P. Y.; Schlegel, H. B.; Frisch, M. J. J. Comput. Chem. 1996, 17, 49. 
(44) Clegg, W.; Elsegood, M.; Teat, S.; Redshaw, C.; Gibson, V. J. Chem. Soc., Dalton Trans. 1998, 3037.

(45) Cernik, R.; Clegg, W.; Catlow, R.; Bushnell-Wye, G.; Flaherty, J.; Greaves, G.; Burrows, I.; Taylor, O.; Teat, S.; Hamichi, M. J. Synchrotron Radiat. 1997, 4, 279.

(46) APEX2; Bruker Nonius: Madison, Wisconsin, 1998.

(47) Cosier, J.; Glazer, A. J. Appl. Crystallogr. 1986, 19, 105.

(48) SAINT, version 7.06a; Bruker AXS Inc.,: Madison, Wisconsin, 2004.
(49) Sheldrick, G. SHELXS97 \& SHELXL97; University of Göttingen: Göttenhen, Germany, 1997.

(50) Bernstein, J.; Davis, R.; Shimoni, L.; Chang, N. Angew. Chem., Int. Ed. Engl. 1995, 34, 1555.

(51) Steiner, T. Angew. Chem., Int. Ed. 2002, 41, 48.

(52) Bondi, A. J. Phys. Chem. 1964, 68, 441.

(53) Rowland, R.; Taylor, R. J. Phys. Chem. 1996, 100, 7384.

(54) Rozas, I.; Alkorta, I.; Elguero, J. J. Phys. Chem. A 1998, 102, 